\title{
REDES SOCIAIS NO CURSO DE CIÊNCIAS CONTÁBEIS DA UNEMAT - CAMPUS DE TANGARÁ DA SERRA.
}

\author{
Maiara Lazzarotto ${ }^{1}$ \\ Laércio Juarez Melz ${ }^{2}$
}

\section{RESUMO}

Desde a última década, o crescimento e a popularização do uso da internet vem se tornando cada vez mais evidente. $\mathrm{O}$ acesso a essa base de dados têm ocorrido das mais variadas formas e para as mais infinitas finalidades, tornando-se assim uma importante ferramenta na divulgação de idéias e conhecimento a nível mundial. Diante do exposto, busca-se analisar, através de entrevistas, de que forma essa nova realidade esta inserida ao meio acadêmico e qual o seu nível de sua utilização, bem como apresentar de que forma a tecnologia pode ser conciliada com os métodos didáticos tradicionais. Apresenta-se a relevância que este trabalho possui para a comunidade, por se tratar de um estudo inédito. Observa-se a popularização das redes sociais e torna-se relevante que a metodologia de ensino passe por readequações. A fim de que possa aprimorar-se, com o objetivo de utilizar a tecnologia disponível para que a aplicabilidade do conhecimento torne-se mais clara, ágil e absoluta.

Palavras Chave: Contabilidade; Ensino Superior; Internet; Mídias Sociais.

\section{INTRODUÇÃO}

A inclusão do uso de computadores na esfera escolar vem agregar aos métodos de ensino agilidade e precisão no processamento de idéias. (RUSHBY, 1985 apud MOREIRA, 2003). Deve-se considerar ainda que a diversidade de informações é ampliada quando aliado ao uso de computadores está o uso da internet. Neste meio virtual no qual se encontra vasta gama de informações que contribuem para o aprendizado. Para Santos (2008), através da internet é possível se ter acesso a especialistas dos mais variados assuntos em diversas partes do mundo. A internet é capaz de derrubar fronteiras geográficas e minimizar tempo na disseminação de conhecimento.

Quando analisado seu uso para fins de pesquisa e estudo no âmbito acadêmico, a realidade é diferente. A maioria dos professores o utiliza apenas para fins particulares, deixando de usufruir desta ferramenta como recurso de ensino em grande escala (GODOY, 1997).

É a internet a grande responsável pelo expressivo crescimento do acesso ao uso do computador. Através dela surgem utilitários e ferramentas que facilitam a rotina e oferecem

\footnotetext{
${ }^{1}$ Acadêmico do curso de Ciências Contábeis da UNEMAT - Campus de Tangará da Serra, maylazzarotto@hotmail.com

${ }^{2}$ Mestre em Engenharia de Produção (UFSCar), Professor do Departamento de Ciências da UNEMAT Campus de Tangará da Serra, laercio@unemat.br
} 
lazer, cultura e entretenimento a população (SANTOS, 2008). Dentre as ferramentas disponíveis, a maior representatividade está no acesso às chamadas redes e mídias sociais, também conhecidas como sites de relacionamento, quais são utilizadas para proporcionar aos seus usuários a oportunidade do compartilhamento de idéias, opiniões e gostos pessoais causando desta forma uma maior interação entre os membros (ROSENBLOON,2011).

Diante deste contexto, a pesquisa teve o objetivo de demonstrar o nível de utilização de redes sociais no meio acadêmico do curso de Ciências Contábeis da Universidade do Estado de Mato Grosso, campus de Tangará da Serra. Paralelamente buscou-se analisar e demonstrar de que maneira e intensidade às novas ferramentas tecnológicas influenciam na rotina diária dos acadêmicos e professores e de que forma elas poderiam vir a colaborar com o aumento na qualidade do aprendizado.

\section{REFERENCIAL TEÓRICO}

\subsection{Metodologia de ensino e o uso do computador no ensino superior}

Conforme a ideologia de Nérici (1992), didaticamente, método é forma como serão traçados os caminhos a serem percorridos a fim de que os objetivos possam ser alcançados. Desta maneira, metodologia de ensino nada mais é do que a forma como ocorre a transmissão de informação e aprendizado do professor para o aluno. Quando voltada para o ensino superior em contabilidade a metodologia de ensino assume a vertente de ser uma forma de transmissão de conhecimento a fim de que estes sejam aplicados a realidade das empresas (MARION; MARION, 2006).

Depende da escolha de uma boa metodologia o sucesso do aprendizado e para tal é necessário que a mesma seja envolvente a atrativa para o público alvo. Segundo o que descreve Marion e Marion (2006) normalmente o que encontra-se presente em sala de aula é metodologia de ensino bastante rígida, não tão atrativa, na qual o aluno apenas recebe a informação que é transmitida pelo professor. $\mathrm{O}$ aluno assume portanto, posição passiva no ciclo de aprendizagem. Dentro desta perspectiva de pensamento, Marion e Marion (2006) defendem, ainda, que deve haver a busca de inovação na transmissão de conhecimento. $\mathrm{Na}$ qual, o aluno possa assumir a posição ativa do aprendizado, para que assim possa ter chances de participar ativamente das análises propostas e seja forçado a expressar suas opiniões, tornando o processo mais interativo e dinâmico. É justamente neste meio que pode ser inserido o uso da informática e consecutivamente o uso da internet. Isso, agilizaria e 
modernizaria a prática do ensino, pois, é evidente o fato de que a metodologia de ensino deve ser constantemente atualizada para não perder a atenção daqueles que estão envolvidos no processo. Para Nérici (1992).

\begin{abstract}
A metodologia do ensino deve ser encarada como um meio e não como um fim, pelo que deve haver, por parte do professor, disposição para alterá-la, sempre que sua crítica sobre a mesma o sugerir. Assim, não se deve ficar escravizado à mesma, como se fosse algo sagrado, definitivo, imutável.
\end{abstract}

Uma metodologia de ensino deve ser composta de três fases: Planejamento, Execução e Avaliação. Nessas fases são compreendidas tarefas como definição da política de ensino e seu conteúdo, execução dos planos traçados e análise a fim de se obter a verificação se os objetivos inicialmente traçados foram atingidos (NÉRICI, 1992).

Para Bogo (2000) Internet é um conjunto de computadores interligados na utilização de um serviço em comum, na busca do compartilhamento de idéias e informações a nível mundial. Desta forma, podemos obter um rápido entendimento do porquê que a mesma é conhecida como "Rede Mundial de Computadores".

Neste ambiente, encontra-se vasta gama de informações, sejam elas políticas, culturais, educacionais, de entretenimento, lazer, sentimentais e infinitos outros temas. Mas nem sempre foi desta maneira. Em seus primórdios, mais aproximadamente no ano de 1969, a internet inicialmente denominada de ARPANET, junção de ARPA - Advanced Research Projects Agency mais o sinônimo de Internet - fora constituída através de um projeto americano que tinha como objetivo interligar universidades, instituições de pesquisa e militares, onde poucos serviços eram disponibilizados, sendo o email o mais utilizado na época. Com o avançar da tecnologia, a Internet foi sendo moldada e tomando formas até chegar ao nível conhecido nos dias atuais (ZEVALLOS JUNIOR, 2009).

No Brasil, o grande boom tecnológico representado pela internet deu-se de forma relevante somente em meados de 1991, ainda que de forma bastante restrita. Foi através da Rede Nacional de Pesquisas, a RNP, que a internet começou a ser utilizada no Brasil. O serviço era inicialmente empregado apenas para interligar universidades aos centros de pesquisa a fim de que se houvesse um maior compartilhamento de idéias. Mas, em 1995 o Ministério de Comunicações e de Ciência e Tecnologia, liberou o acesso do serviço para escala comercial através de conexões que eram negociadas com a RNP e a Embratel (ZEVALLOS JUNIOR 2009). 
Para Godoy, (1997), “embora os professores façam uso constante do computador para realizar suas pesquisas e trabalhos individuais, poucos se lembram dele enquanto recurso para o ensino". Godoy (1997) define desta forma o que ocorre com a maioria dos docentes. Embora a evolução tecnológica cresça dia após dia, influenciando cada vez mais toda a população, esse crescimento não tem sido acompanhado pelas universidades brasileiras.

Um dos maiores ponto de discussão sobre o aceite ou não da inclusão da internet e suas ferramentas no ensino do meio acadêmico esta no fato dela apresentar algumas desvantagens ditas como relevantes por estudiosos da área. Segundo Godoy (1997), a internet faz com que se perca a vivacidade social existente entre as pessoas, pois, tudo torna-se muito frio e impessoal. Fica evidente, contudo, que o uso da internet faz com que a troca de informação ocorra de maneira muito mais ágil e eficiente, auxiliando no rápido processamento de idéias (RUSHBY, 1985 Apud MOREIRA, 1997).

Buscando aproveitar de maneira produtiva a agilidade disponibilizada pela internet, surgem a pequenos e lentos passos à idéia de se agregar as redes sociais ao meio de ensino. Exemplo, que segundo Moran (1997) é o encontrado na Escola do Futuro, grupo de pesquisa da Universidade de São Paulo pioneiro na área de desenvolvimento de projetos relacionados ao ensino de ciências e humanidades através de redes telemáticas no ensino fundamental e médio, desde 1990. Os resultados obtidos com processos avaliativos, demonstram que a prática adotada aumenta o interesse e a motivação do aluno para o desenvolver da pesquisa, a sensibilidade para o uso de novas tecnologias, para a busca por novas amizades e pelo estudo da língua inglesa. A maior dificuldade enfrentada pelo projeto está em promover a continuidade especialmente na rede pública brasileira, por deficiência em equipamentos e professores que possam monitorar o projeto (MORAN, 1997).

Defensor desta bandeira, Moran (1997), descreve ainda que práticas como a desenvolvida no projeto Escola do Futuro e a inserção das redes sociais podem e devem ser utilizadas no ambiente escolar e conseqüentemente acadêmico como forma de agregação ao currículo e a proposta de aprendizado, desde que, todo este desenvolver apresente a intervenção de um gestor, como forma de orientar e verificar se os objetivos propostos estão sendo buscados. Pois, em toda navegação e consecutivamente toda pesquisa realizada em um ambiente virtual é necessário utilizar-se de um censo crítico ao filtrar informações ditas como relevantes ou não. 
Um exemplo bastante prático, citado por Moran (2011) relacionado ao ensino da língua portuguesa e aos fatos que geralmente ocorrem quando há a tentativa de se aliar tecnologia ao ensino, afirmando que ao se 'brincar' no Twitter o conteúdo de síntese gerado pelos alunos é desperdiçado pelo professor, ao deixar de utilizá-lo como, por exemplo, oportunidade para treinar a prática do resumo de idéias.

Segundo publicação da Revista Veja.com (2009) as redes sociais permitem que seus usuários se comuniquem e troquem informações de forma muito rápida, tudo ao alcance de um simples clique. Redes Sociais, também conhecidas como sites de relacionamento são, segundo Telles (2010):

[...] ambientes que focam reunir pessoas, os chamados membros, que uma vez inscritos, podem expor seu perfil com dados como fotos pessoais, textos, mensagens e vídeos, além de interagir com outros membros, criando lista de amigos e comunidades.

São exemplos de rede sociais, citados por Telles (2010): Orkut, Facebook e MySpace.

Mídias social por sua vez, é o compartilhamento de vídeos, músicas, imagens e textos a fim de que se amplie o conhecimento entre aqueles que promovem a interação. (DUBNER, 2011). Segundo Dubner (2011) a própria tradução do termo Social Media para o português pode ser entendido como “[...] uso do meio eletrônico para interação entre pessoas”. Diferente da Redes Sociais, para se obter uma Mídia Social não é necessário que se crie uma conta de usuário/perfil.

Conforme Telles (2010) e também ressaltado por Altermann (2010), as mídias sociais não surgiram a pouco tempo. Desde o seu principio eram utilizadas para divulgar um fato a sociedade como um todo ou a um pequeno grupo que interessasse.

São exemplos de Mídias Sociais citados por Telles (2011) e Hellmann (2008): Twitter, Youtube, Wikipédia, Second Life, Upcoming, Flickr entre outros. A função das redes e mídias pode ser observada no quadro 1 . 


\begin{tabular}{|c|c|}
\hline Ferramenta & Função \\
\hline Orkut & $\begin{array}{l}\text { Rede Social e site de discussão operado pelo Google, é considerada a maior rede social } \\
\text { do Brasil. Segundo o Ibope, aproximadamente } 91 \% \text { dos usuários de redes sociais possuem um } \\
\text { perfil neste site. }\end{array}$ \\
\hline Facebook & $\begin{array}{l}\text { Utilidade social possui a função de conectar pessoas, sejam elas amigas ou que } \\
\text { trabalham, estudam e convivem entre si. Ou ainda como diz o slogan do site: "No Facebook você } \\
\text { pode se conectar e compartilhar o que quiser com quem é importante em sua vida". }\end{array}$ \\
\hline MySpace & $\begin{array}{l}\text { Voltado para o entretenimento social, mídia representada pelo perfil de pessoas que } \\
\text { compartilham suas preferências e opiniões sobre música, filmes, televisão entre outros. }\end{array}$ \\
\hline Twitter & $\begin{array}{l}\text { Rede Social similar a um microblog, onde são publicadas mensagens instantâneas de } \\
\text { compartilhamento entre os chamados 'seguidores'. }\end{array}$ \\
\hline YouTube & $\begin{array}{l}\text { Mídia Social, onde é permitido aos seus usuários o compartilhamento de vídeos. Neste } \\
\text { tipo de serviço, é necessário ter uma conta apenas para os usuários que desejam compartilhar seus } \\
\text { vídeos pessoais, caso o contrário o acesso ao conteúdo é livre. }\end{array}$ \\
\hline Wikipédia & $\begin{array}{l}\text { Enciclopédia livre e gratuita reúne as mais diversas informações sobre os mais diversos } \\
\text { assuntos. }\end{array}$ \\
\hline Second Life & $\begin{array}{l}\text { Por muitos visto como um jogo, por outros um simulador da vida real ou ainda como } \\
\text { exemplo de mídia social, conforme a tradução do nome já menciona é a 'Segunda Vida' } \\
\text { demonstrada em um ambiente virtual que representa praticamente todas as tarefas desenvolvidas } \\
\text { por um ser humano. }\end{array}$ \\
\hline Upcoming & $\begin{array}{l}\text { Site, onde é atribuído aos seus usuários o poder de criar uma agenda ou calendário de } \\
\text { eventos para que possa ser compartilhado com os seus amigos. }\end{array}$ \\
\hline Flickr & Referencial em compartilhamento de imagens. \\
\hline LinkedIn & $\begin{array}{l}\text { Comparado à uma rede social, é uma rede de negócios utilizada principalmente por } \\
\text { profissionais que buscam compartilhar conhecimento, informações, novas oportunidades de } \\
\text { emprego e reencontrar antigos colegas. }\end{array}$ \\
\hline
\end{tabular}

Quadro 1. Algumas definições e objetivos dos exemplos de Redes e Mídias Sociais.

Fonte: Wikipédia (2011), Facebook (2011).

Estima-se que, no ano de 2011, encontram-se mais de 35 milhões de internautas em território nacional, que representam aproximadamente $18 \%$ do total da população do país. Esses internautas consomem em média 34 horas mensais em navegação,(CETIC, 2011). O que faz com que o Brasil ocupe a $5^{\text {a }}$ colocação no ranking mundial de conexões à internet (ANTONIOLI, 2011).

A tabela 1, mostra a evolução do número de internautas e horas de acesso desde de janeiro de 2001 até março de 2011. Pode-se analisar o crescimento que ocorreu nestes anos: 
Tabela 1. Tabela Comparativa entre internautas ativos domiciliares e horas navegadas no Brasil entre janeiro de

\begin{tabular}{|c|c|c|c|c|c|c|c|c|c|c|c|}
\hline Descrição & 2001 & 2002 & 2003 & 2004 & 2005 & 2006 & 2007 & 2008 & 2009 & 2010 & 2011 \\
\hline $\begin{array}{l}\text { Internautas } \\
\text { (em milhões) * }\end{array}$ & 5,0 & 7,2 & 7,5 & 12,3 & 11,0 & 14,1 & 16,3 & 22,7 & 25,4 & 29,1 & 35,1 \\
\hline $\begin{array}{l}\text { Tempo } \\
\text { (em horas)** }\end{array}$ & $07: 31$ & 09:01 & 11:04 & $13: 15$ & $14: 57$ & 19,24 & $20: 54$ & $23: 51$ & $24: 06$ & $32: 34$ & $34: 06$ \\
\hline
\end{tabular}

Ao realizar a análise do número de internautas conectados e suas respectivas horas navegadas, se considerado o ambiente de trabalho agregado ao ambiente domiciliar, o número de navegadores cresce para mais de 43 milhões. A maioria destes internautas passam aproximadamente 48 horas conectados por mês, representando assim, aproximadamente $20 \%$ do total de horas/mês (CETIC, 2011). Segundo o Ibope (2011, apud CETIC, 2011) aproximadamente 51,88\% dos internautas brasileiros são do sexo masculino enquanto aproximadamente $48,12 \%$ pertencem ao sexo feminino.

De acordo com a pesquisa realizada em meados de agosto de 2010 pelo Ibope Nielsen e Interactive Advertising Bureau Brasil e divulgada na revista Exame, aproximadamente 98\% do total de internautas utilizam os serviços de internet e acessam suas redes sociais em casa, sendo que deste percentual, aproximadamente 54\% realizam seus acessos mais de uma vez por dia. A revista Exame.com (2011), concluiu que a maioria da população que acessa as redes sociais utilizam-se desta ferramenta para efetuar a troca de informações entre amigos ou por lazer e entretenimento e em sua maioria, aproximadamente $28 \%$, possuem idade entre 25 e 34 anos.

Outro número também divulgado pela Exame.com (2011) de dados coletados pela E.life (2011) indicam o crescente aumento no número de acessos a internet realizados através de aparelhos celulares. Segundo a publicação da revista Exame.com (2011), em Março de 2011, os dados levantados indicam que aproximadamente $44,80 \%$ dos usuários de redes sociais presentes no Brasil realizam seus acessos através dos seus aparelhos, enquanto no ano de 2010 este número representava apenas $34,40 \%$.

Quando delimitada a pesquisa apenas ao número de acessos as redes e mídias sociais, percebe-se que o Orkut.com é considerada a rede social de maior acesso no Brasil. Fato este, que segundo especialistas deve mudar, pois o Facebook vem sendo apontado como o sucessor do Orkut.com devido ao crescente número de acessos realizados pelos brasileiros. Em $2^{\circ}$ e $3^{\circ}$ 
lugar no ranking nacional de redes e mídias sociais mais acessadas no país, encontra-se o Facebook e o Twitter, respectivamente (KARASINSKI, 2010).

De acordo com dados divulgados pela Nielsen (2011, apud Rosenbloom, 2011) “[...] as redes sociais são agora a atividade online mais popular, à frente do envio de e-mails, pesquisas online e jogos". Rosenbloom (2011) exemplifica que, de cada 4 minutos de conexão o usuário deste serviço passa 1 minuto conectado a sua rede social.

O crescimento na utilização da internet no território brasileiro faz com que a tecnologia relacionada a essa área cresça equiparadamente, buscando atender a uma gama de consumidores cada dia mais exigentes (BETAT, 2006). Estão disponíveis no mercado, os mais modernos modelos de computadores e as mais variadas formas de conexão, podendo ser via satélite, via modem $3 \mathrm{G}$, via sinal de televisão e os clássicos sinais via rádio e modem via cabo.

Diante de expressivos números, não há como se negar a importância que a internet e seus afluentes possuem perante a sociedade. Conforme já citado, a mesma é capaz de modificar cenários, divulgar fatos, notícias quase que em momento real, tudo a um simples clique e ao alcance de praticamente toda a população (SANTOS, 2008).

Desta forma, não há como negar, que os métodos didáticos devem passar por uma repaginação, devendo haver uma atualização e parametrização para que figurem de forma compatível com a sociedade atual.

\section{METODOLOGIA}

A pesquisa apresentada possui caráter exploratório, que se torna propício pela pouca informação disponível sobre o tema. Conforme Gil (2002) este estudo proporciona ao pesquisador maior proximidade com o problema. Desta maneira, ao aprofundar-se mais no assunto estudado o pesquisador pode aprimorar seus pensamentos e ampliar seus conhecimentos.

Quanto aos procedimentos, foi utilizada a ferramenta de levantamento de dados, através de entrevistas. Assim como, também foi utilizada a pesquisa bibliográfica, que de acordo com Oliveira (1999) é considerada uma pesquisa de caráter amplo, permitindo que o pesquisador se utilize tanto da pesquisa de campo quanto da pesquisa laboratorial. Deste modo, foram utilizados artigos científicos, periódicos, livros e as mais diversas fontes de pesquisa já elaboradas por outrem. 
Alguns conceitos somente puderam ser obtidos pelo site da Wikipédia, enciclopédia digital de livre edição. Entende-se que, apesar de ser considerada fonte não científica, foi a única fonte que apresentou os conceitos procurados. O caráter inovador e exploratório desta pesquisa justifica, portanto, o uso desta fonte disponível.

A abordagem do tema tem como característica a quantitativa por se utilizar de cálculos na busca de quantificar dados. Segundo Oliveira (1999, p. 115) a abordagem quantitativa de uma forma geral proporciona "[...] a precisão nos resultados, e evitando com isso distorções de análise e interpretações."

Os resultados analisados foram coletados por meio de questionários aplicados tanto na parte docente quanto na parte discente da instituição, durante o mês de Junho do ano de 2011. Compõem a mensuração desta pesquisa, 169 opiniões de acadêmicos que compõem o curso de Ciências Contábeis da Universidade do Estado de Mato Grosso, campus universitário de Tangará da Serra e 13 opiniões entre os professores que ministraram aulas para o referido curso no período letivo 2011/01. A pesquisa foi direcionada a todos os semestres e a toda faixa etária que a compõem. Foram analisados fatores que caracterizam o acesso à internet desta população. Desta forma, foi possível caracterizar e analisar se o mesmo sofre influência variada de acordo com a idade, por exemplo, ou se o mesmo ocorre de forma homogênea.

Foram analisadas as principais redes e mídias sociais, sendo elas: Orkut, Facebook, My Space, Twitter, YouTube, Wikipédia, Second Life, Upcoming, Flickr, LinkedIn. Buscando compreender desta forma, qual rede ou mídia social está mais presente na vida do acadêmico. Foi através desses dados que foram analisadas formas de inclusão dessas ferramentas ao meio didático do ensino superior.

Buscando facilitar, agilizar e garantir a harmonia do processo de coleta de dados foi elaborado um fluxograma das etapas de execução da pesquisa, conforme segue. 
Figura 01. Etapas da Pesquisa.

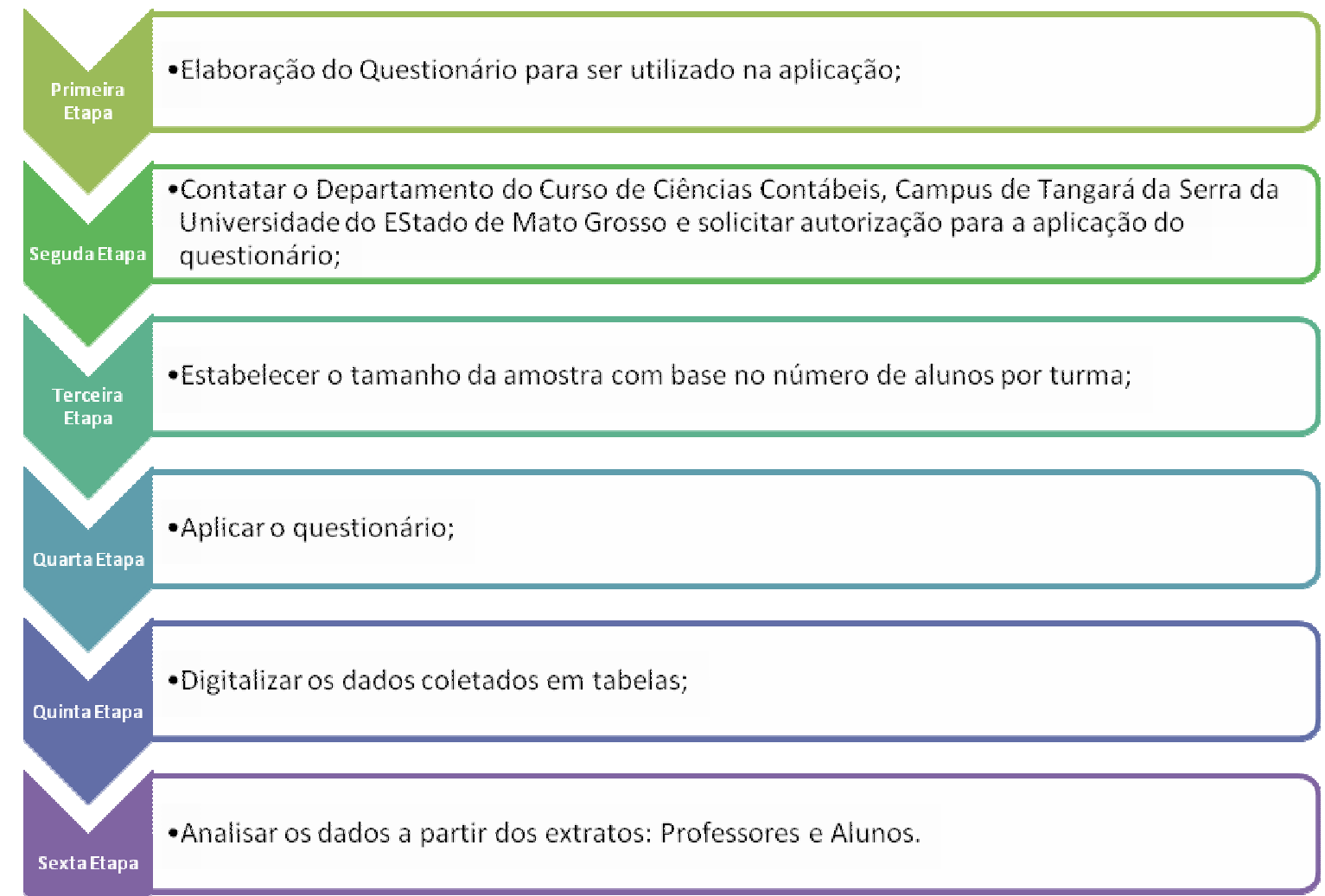

\section{DISCUSSÃO DE RESULTADOS}

Nesta seção apresentam-se: as características dos entrevistados e do uso de equipamentos realizado pela população em estudo, a caracterização do uso de redes sociais entre os entrevistados e a inserção das redes e mídias sociais no meio acadêmico.

\subsection{Características da amostra}

Através da coleta e análise dos questionários aplicados pode-se observar diversidade etária entre os discentes da instituição. Aproximadamente $36 \%$ dos acadêmicos, 61 componentes, do curso em análise estão na faixa etária que compreende a idade de 18 a 21 anos e outra parcela igualitária de $36 \%$ abrangentes entre a idade entre 24 e 35 anos. Demonstrando desta forma, o fluente interesse pela especialização presente entre os jovens e entre aqueles que já possuem uma vida profissional mais ativa, bem como o fato do curso analisado ser atrativo a essa vertente. Entre os docentes da instituição, observa-se uma faixa etária mais elevada, $85 \%$ dos entrevistados mencionaram que possuem idade superior a 35 anos. Essa característica demonstra possível idéia de que o interesse pela magistratura venha a 
ser despertado após amadurecimento na profissão, através do aprimoramento do conhecimento adquirido no período acadêmico com atividades desenvolvidas na área.

Tem-se o conhecimento que a sociedade busca a igualdade entre os sexos. Observa-se que a mulher têm se feito cada vez mais presente em universos que antigamente eram tidos como exclusividade masculina, tais como: direito a ensino superior, direito a voto, acesso a grandes cargos em organizações entre outros. Essa tendência é visualizada na pesquisa realizada. Ainda que a maioria dos entrevistados pertença ao sexo masculino, a presença feminina se faz presente em forma significativa. Entre o público entrevistado, cerca de $45,05 \%$ destes pertencem ao sexo feminino, conforme pode-se observar nas tabelas 02 e 03 .

Tabela 02. Idade versus Sexo - Amostra populacional acadêmica. Tangará da Serra, 2011.

\begin{tabular}{cccc}
\hline Idade & Feminino & Masculino & Total \\
\hline Acima de 35 anos & 5 & 8 & 13 \\
De 15 a 17 anos & 2 & 2 & 4 \\
De 18 a 21 anos & 30 & 31 & 61 \\
De 22 a 24 anos & 11 & 17 & 28 \\
de 24 a 35 anos & 30 & 31 & 61 \\
Não desejo responder & & 1 & 1 \\
Não respondeu & & 1 & 1 \\
Total geral & $\mathbf{7 8}$ & $\mathbf{9 1}$ & $\mathbf{1 6 9}$ \\
\hline
\end{tabular}

Fonte: Dados coletados pelo autor.

Tabela 03. Idade versus Sexo - Amostragem populacional docente. Tangará da Serra, 2011

\begin{tabular}{cccc}
\hline Idade & Feminino & Masculino & Total \\
\hline Acima de 35 anos & 2 & 9 & 11 \\
De 24 a 35 anos & 2 & & 2 \\
Total geral & $\mathbf{4}$ & $\mathbf{9}$ & $\mathbf{1 3}$ \\
\hline
\end{tabular}

Fonte: Dados coletados pelo autor.

Quando utiliza-se a internet, assim o faz com alguma finalidade e esse foi um dos questionamentos levantados aos entrevistados. Depois de realizada a caracterização da população buscou-se analisar pontos relacionados ao mundo virtual, ponto foco da pesquisa. Desta forma, identificou-se que tanto os acadêmicos quanto os professores buscam adquirir conhecimento em áreas diversas, bem como buscam o entretenimento durante as suas horas navegadas. O conhecimento desejado pelos entrevistados não significa ser conhecimento voltado totalmente para a área contábil. Esse conhecimento pode ser relacionado a áreas de línguas, informática, culinária por exemplo. Pode-se obter melhor visualização na figura 02 . 
Figura 02. O que os acadêmicos e professores buscam na internet. Tangará da Serra, 2011.

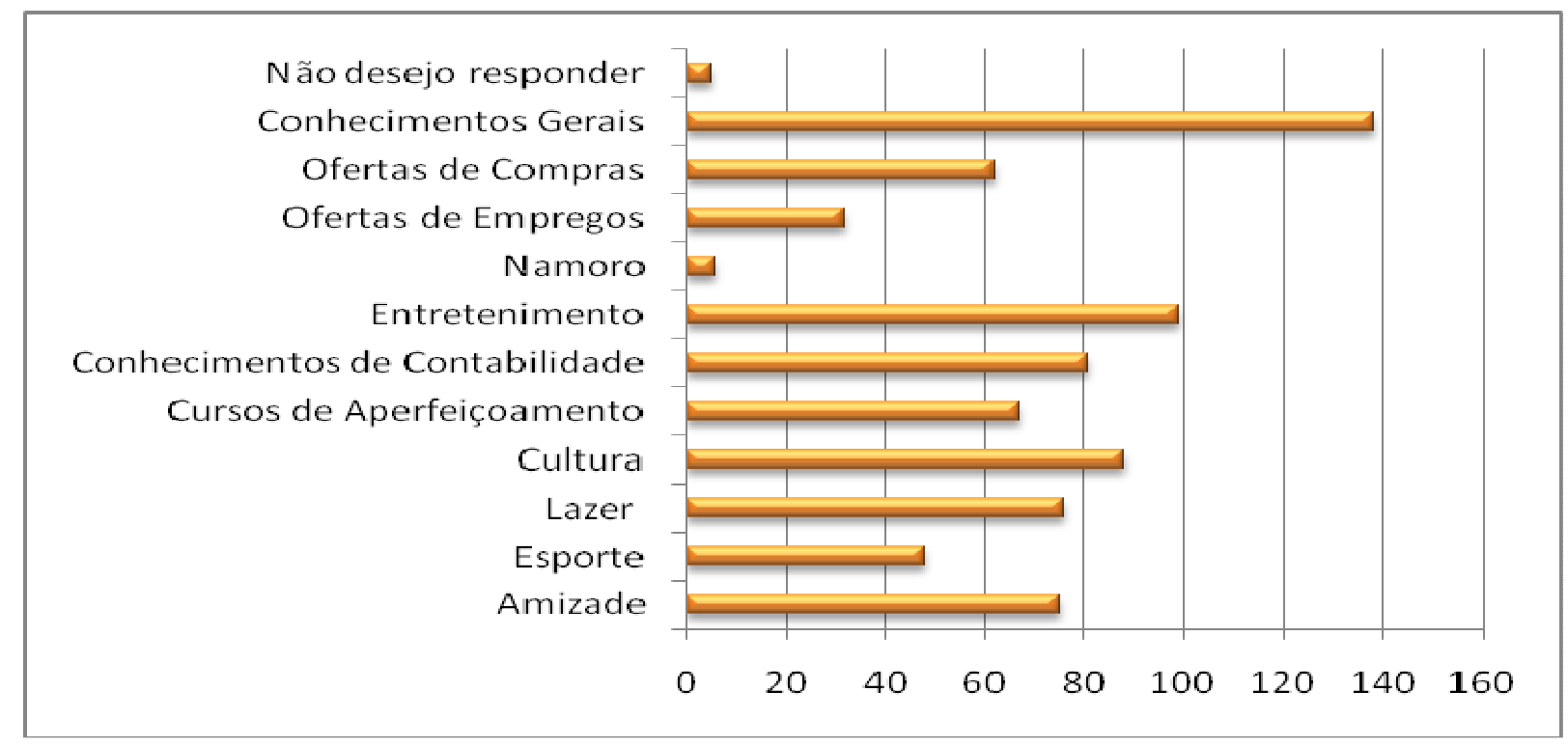

Fonte: Dados coletados pelo autor.

\subsection{Uso de equipamentos}

O crescente avanço tecnológico acompanhado com o passar das gerações pode também ser visualizado através da pesquisa. A cerca de pouco mais de uma década, pequena parcela da população possuía acesso e, ainda, sequer conhecimento do que se tratava um aparelho celular ou computador. Nos anos 2000 a situação sofreu reversão. A pequena parcela da população não é aquela que não possui acesso e conhecimento, mas sim aquela que não usufrui dos benefícios propostos por esses aparelhos em seu lar, fazendo parte da sua rotina.

Exemplo relevante da realidade é explicita na presença maciça dos aparelhos celulares na rotina dos professores da instituição. 100\% destes utilizam esse aparelho em seu dia a dia, seja para desenvolver as atividades básicas que o objeto propõem, seja para acessar a internet e redes sociais com mobilidade. Entre os acadêmicos, este aparelho perde apenas para o uso dos tradicionais aparelhos televisores, clássico objeto presente nos lares brasileiros. 
Figura 03. Itens domésticos mais expressivos na rotina do discente. Tangará da Serra, 2011.

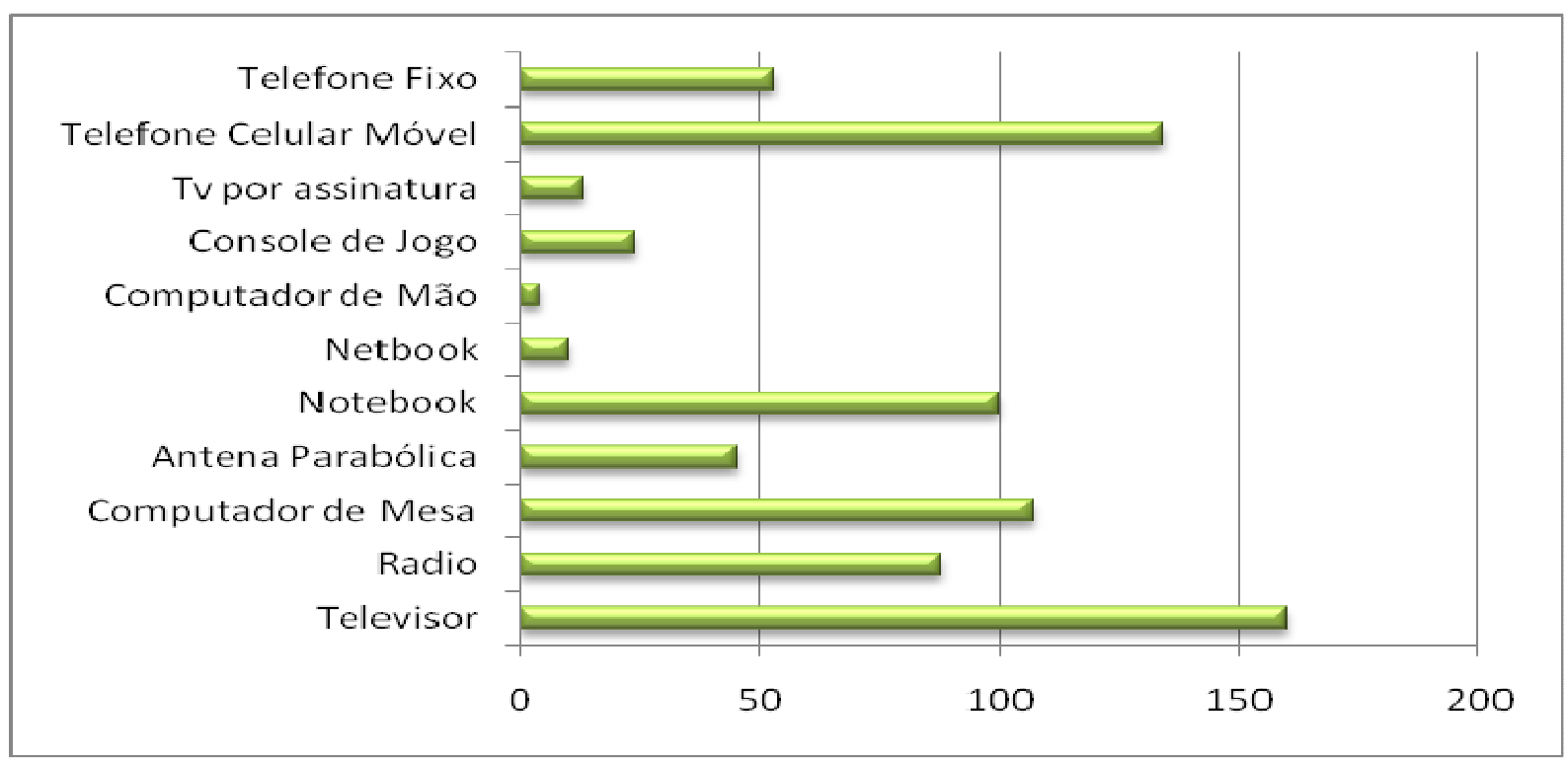

Fonte: Dados coletados pelo autor.

Figura 04. Itens domésticos mais expressivos na rotina do docente. Tangará da Serra, 2011.

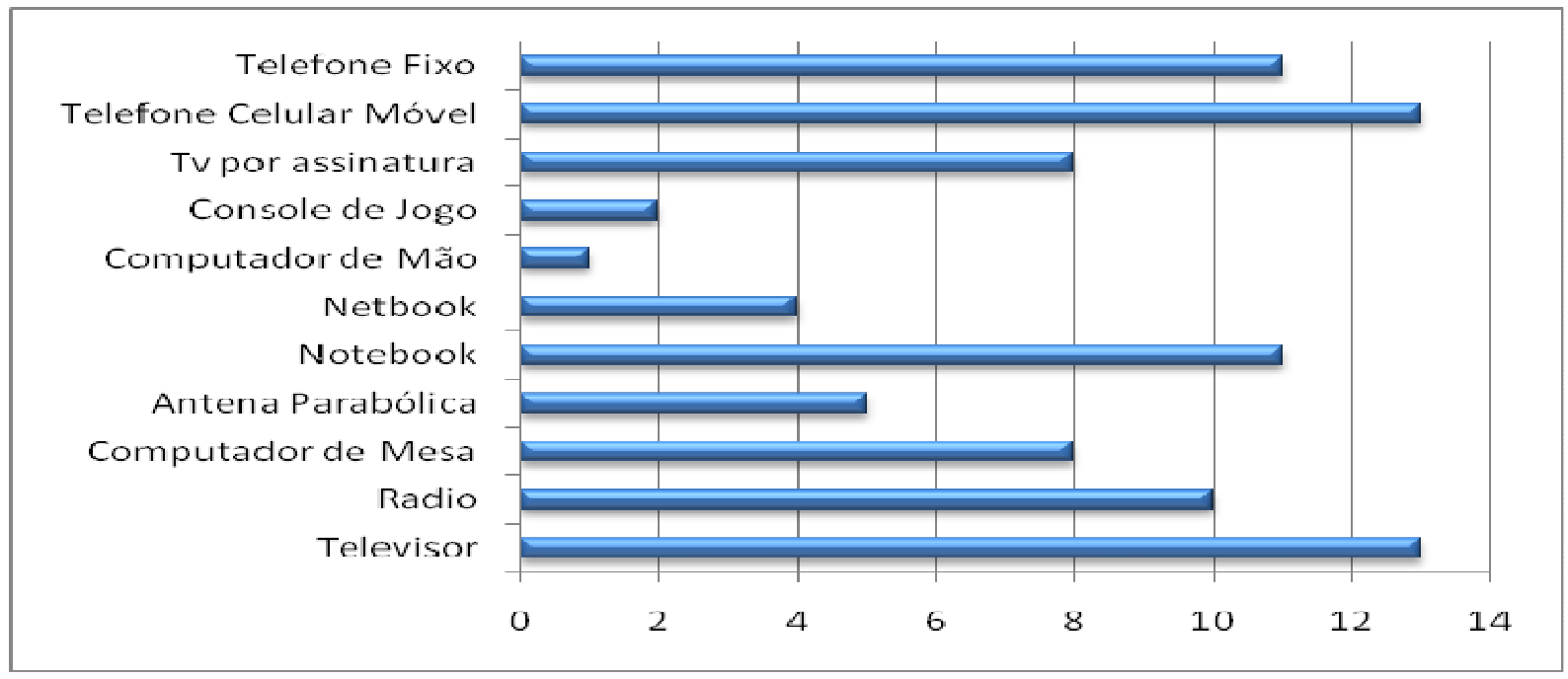

Fonte: Dados coletados pelo autor.

A presença do avanço tecnológico pode ser visivelmente concretizada no lar de cada brasileiro, através, por exemplo, de utensílios domésticos cada dia mais funcionais. As empresas do ramo estão empenhadas em oferecer ao seu público alvo uma maior mobilidade, praticidade e conforto. Nessa vertente que pode-se observar a substituição dos computadores de mesa pelas suas versões portáteis. Os cada vez mais conhecidos laptops e netbooks, e aparelhos de telefonia móvel. Acompanhando essa realidade, as empresas de transmissão do sinal de internet estão também em busca da modernização. Para garantir mercado, estão 
ofertando seus serviços através de unidades removíveis, os chamados modems $3 \mathrm{G}$, que transmitem o sinal conforme uma sistemática similar ao utilizado em telefonia móvel, permitindo uma maior liberdade aos seus usuários.

Com o desenvolver do uso do aparelho celular, observa-se que a utilização deste como meio de conexão a rede mundial de computadores tem se tornando cada dia mais conhecido entre os entrevistados. Aproximadamente 54\%, dos acadêmicos e professores admitiram que seus aparelhos possuem acesso a rede mundial de computadores. Contudo, em muitos casos o uso dessa ferramenta ainda apresenta-se de forma discreta, apenas $8 \%$ dos entrevistados que possuem aparelho móvel com tecnologia compatível o utilizam com essa finalidade. Dos aproximados 91 entrevistados que afirmaram possuir aparelhos de telefonia móvel com acesso a internet apenas 7 destes realiza efetivamente o acesso. A maioria dos casos ainda ocorre em computadores de mesa instalados em ambientes domésticos ou profissionais.

\subsection{Uso de redes sociais}

Pode-se no estudo, revalidar dados já apresentados por pesquisas realizadas em nível nacional. A rede social de maior utilização tanto entre acadêmicos quanto professores é o Orkut, enquanto o YouTube demonstrou ser o representante da mídia social nesse comparativo. O diferencial entre ambos encontra-se na freqüência com que estes aplicativos são acessados. Enquanto os acadêmicos praticam acessos diários, ou ainda, que apenas nos finais de semana, os docentes da instituição são responsáveis por realizar um único acesso mensal. O motivo para essa diferenciado pode ocorrer devido a faixa etária, a rotina diária, a constituição familiar, a rotina profissional entre outros.

Notou-se a confirmação da vertente já levantada por especialistas, o Facebook tem número de acessos similar ao Orkut entre os professores do curso e esta em ascensão entre os acadêmicos, vindo possivelmente a substituí-lo. O motivo mais freqüente apresentado pelos especialistas para que possível substituição ocorra, é a qualidade de interação disponível para os usuários do Facebook. 
Figura 05. Redes e mídias sociais mais utilizadas pelos acadêmicos. Tangará da Serra, 2011.

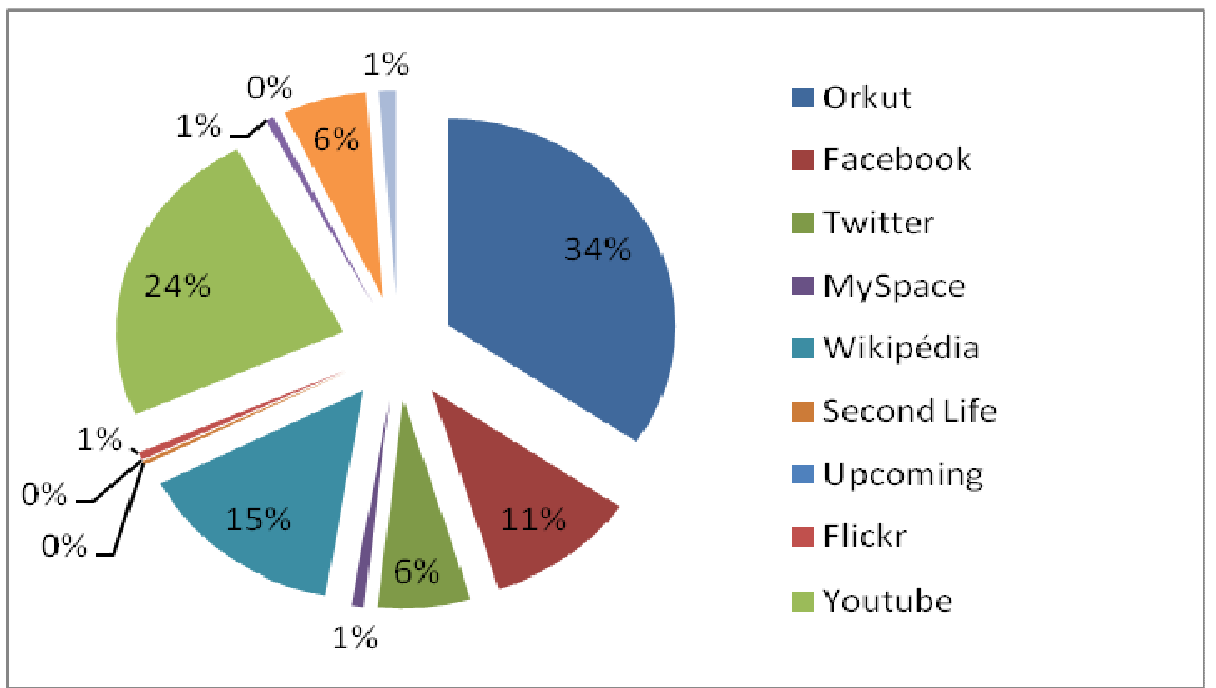

Fonte: Dados coletados pelo autor.

Figura 06. Redes e mídias sociais mais utilizadas pelos professores. Tangará da Serra, 2011.

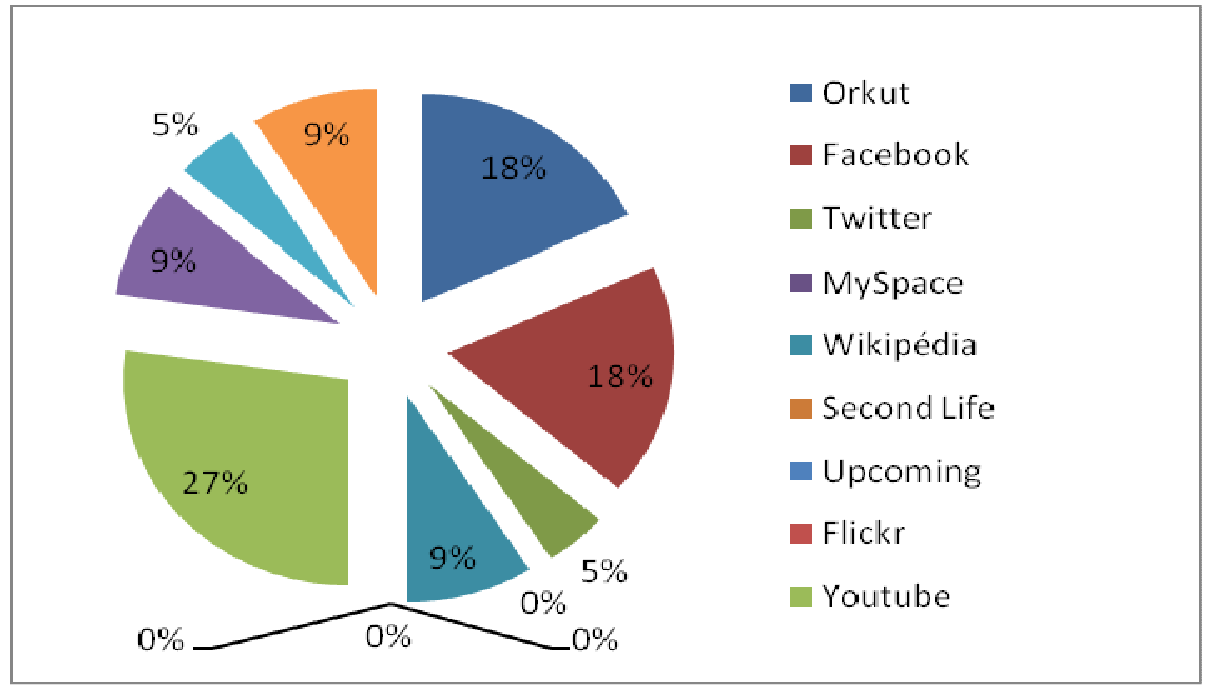

Fonte: Dados coletados pelo autor.

\subsection{Inserção das redes e mídias sociais a meio acadêmico}

Sabe-se que as redes e mídias sociais são capazes de proporcionar rapidez na troca de idéias e no cessar de dúvidas, podendo desta forma, contribuir para a melhoria na qualidade do ensino. Logo, acredita-se que tais ferramentas se aplicadas da forma devida são capazes de contribuir de forma significativa na redução da insatisfação presente entre os professores do curso, quando relacionado ao processo de troca de informações. 
Há o interesse tanto da parte docente quanto da parte discente da instituição em contribuir para que tal nível insatisfatório possa ser minimizado. Ambas as partes assumiram que compartilhariam dados em redes sociais entre si e se fazem favoráveis a inclusão da internet e suas ferramentas em sala de aula.

Um dos mais significativos propósitos deste artigo foi o de levantar sugestões que viessem apresentar formas para a interação entre internet e ensino. Desta forma, para alcançar esse objetivo, foi colocado a disposição para análise do público entrevistado, as seguintes sugestões: a inclusão de um fórum de discussão no site (já existente) do departamento do curso, a criação de um site especifico do acadêmico ou ainda a criação de um blog. Todas as sugestões visaram propor o beneficio da agilidade na troca de informações que a internet dispõe. A sugestão mais aceita tanto pelos acadêmicos quanto pelos professores foi a da inclusão do fórum de discussão. Tal fórum de discussão funcionaria similar a um chat (sistema que possibilita o envio de mensagens instantâneas) onde professores e acadêmicos poderiam compartilhar dúvidas e conhecimento em tempo real.

Nas tabelas 4 e 5, pode-se visualizar a mensuração das opiniões coletadas. Torna-se importante ressaltar que a totalidade das opiniões não é compatível com a totalidade de entrevistados pelo fato das tabelas serem confeccionadas no sistema de sugestão.

Tabela 04. Mecanismo de inserção sugerido pelo acadêmico. Tangará da Serra, 2011.

\begin{tabular}{cccc}
\hline Mecanismo & Feminino & Masculino & Total \\
\hline Blog & 11 & 17 & 28 \\
Site do Acadêmico & 42 & 37 & 79 \\
Fórum de discussão & 32 & 55 & 87 \\
Total geral & 85 & 109 & $\mathbf{1 9 4}$ \\
\hline
\end{tabular}

Fonte: Dados coletados pelo autor.

Tabela 05. Mecanismo de inserção sugerido pelo professor. Tangará da Serra, 2011.

\begin{tabular}{cccc}
\hline Mecanismo & Feminino & Masculino & Total \\
\hline Blog & 2 & 3 & 5 \\
Site do Acadêmico & 2 & 4 & 6 \\
Fórum de discussão & 2 & 7 & 9 \\
Total geral & 6 & 14 & $\mathbf{2 0}$ \\
\hline
\end{tabular}

Fonte: Dados coletados pelo autor.

Visando permitir que o entrevistado pudesse dispor de sua opinião, na ferramenta utilizada foi disponibilizado um espaço onde este poderia incluir sua própria sugestão, se 
assim a houvesse. Várias idéias relevantes foram apresentadas. Tanto acadêmicos quanto professores concordaram ao afirmar que a internet poderia contribuir para que houvesse uma maior interação entre as partes em sala de aula, fazendo com que a aula dita como passiva viesse a assumir uma forma mais dinâmica e prática. Ambos concordaram que seria de valia e relevância se o acesso a internet fosse disponibilizado a fim de que pesquisas em sites relacionados ao curso pudessem ser usufruídas durante a aula, ou seja, durante a produtiva troca de idéias. Ambos também afirmaram, com freqüência, que seria interessante se vídeos e/ou palestras fossem ministrados durante a transmissão de conhecimento e se houvesse a implantação de simulados durante o curso, pois, contribuiriam na assimilação do assunto ministrado à realidade.

Figura 07. Sugestões de inserção acadêmicos e professores. (Tangará da Serra, 2011)

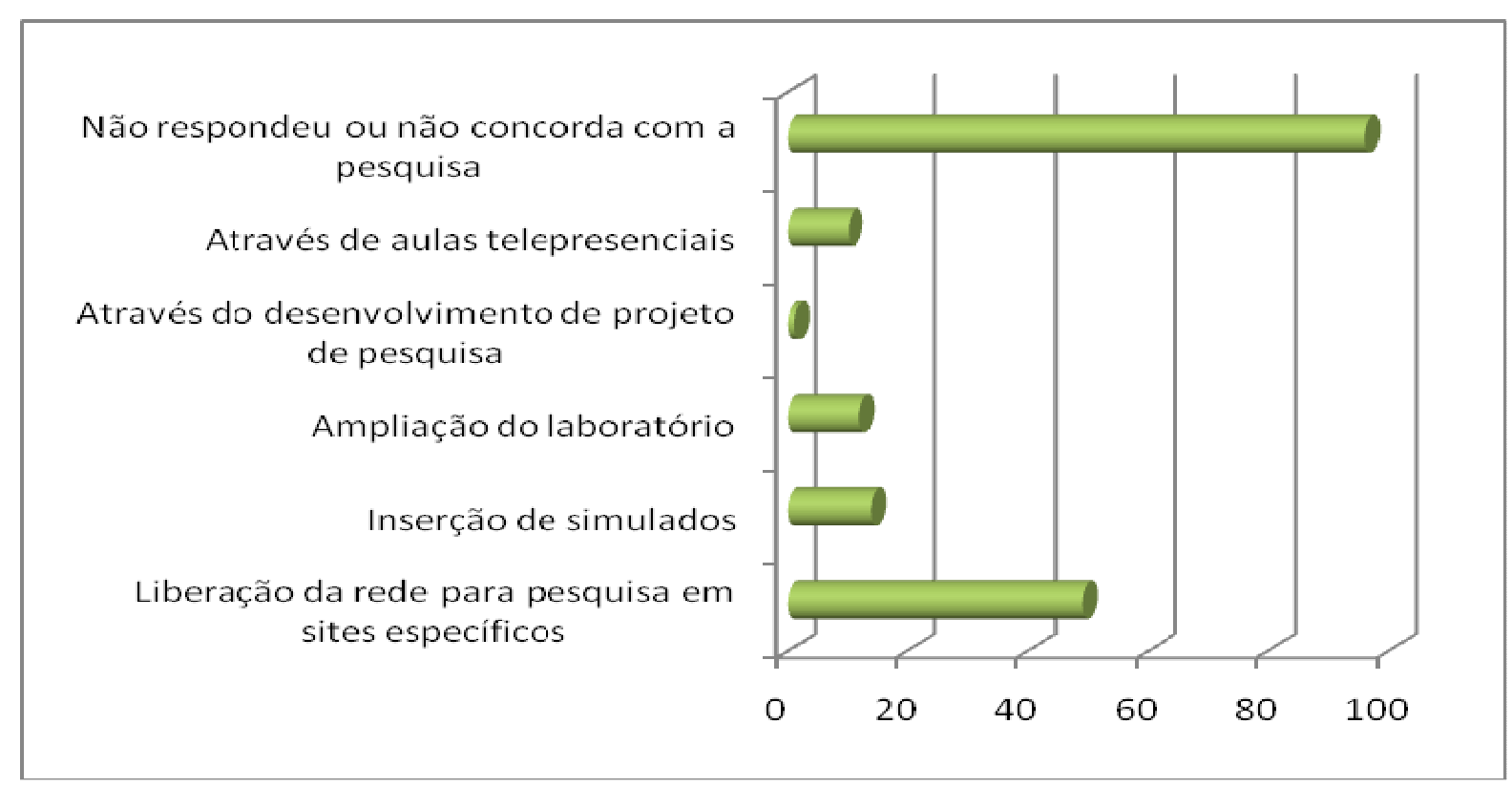

Fonte: Dados coletados pelo autor.

\section{CONSIDERAÇÕES FINAIS}

De acordo com os dados coletados, tornou-se aceitável a idéia de que a internet de uma maneira ampla e geral está cada vez mais presente na rotina da população brasileira. Assim como é aceitável afirmar que as redes sociais vêm assumindo um papel não somente de entretenimento mas de conhecimento, aprendizado e aprimoramento profissional. Desta forma, é inaceitável que em um espaço onde o avanço tecnológico vêm a contribuir grandiosamente se utilizado da maneira correta, ao invés de ser inserido nas metodologias de ensino é em muitos casos barrado, encontrando forte resistência pelas partes gestoras. 
Acredita-se que além da inclusão de um fórum no site do departamento bem como a futura elaboração de um site voltado para a parte discente do curso, a idéia de que fossem inseridos em sala de aula os simulados disponíveis em sites relacionados ao curso, pois, estes trariam para o ambiente educativo vivacidade e o despertar do interesse acadêmico em construir o aprendizado.

É necessário uma reavaliação da realidade das instituições de ensino, que de acordo com Santos (2008) recebem o 'novo' de forma atrasada e defasada, e o aceitam apenas após este já ocupar-se das rotinas pessoais e profissionais dos usuários. É preciso haver coerência, bom senso e um grande nível crítico ao saber selecionar as informações que nos estão disponíveis pelos mais variados meios de comunicação, é preciso saber avaliar o que é e o que não é construtivo para o conhecimento.

\section{REFERÊNCIAS}

ALTERMANN, Dennis. Qual a diferença entre redes sociais e mídias sociais?.2010. Disponível em: <http://www.midiatismo.com.br/comunicacao-digital/qual-a-diferenca-entreredes-sociais-e-midias-sociais> Acesso em 21 de Outubro 2011.

ANTONIOLI, Leonardo. Estatísticas, dados e projeções atuais sobre a internet no Brasil. 2011. Disponível em: <http://www.tobeguarany.com/internet_no_brasil.php>. Acesso em: abril 162011.

BETAT, Fabiana. A internet como avanço tecnológico na comunicação. Disponível em: <http://fabbiannyy.blogspot.com/2006/09/internet-como-avano-tecnolgico-na.html> Acesso em: 29 agosto 2011.

BOGO, Kellen. C. A História da Internet - Como Tudo Começou. 2011. Disponível em: $<\mathrm{http}$ ///kplus.cosmo.com.br/materia.asp?co=11\&rv=Vivencia >. Acesso em: 16 abril 2011.

CETIC.BR. Centro de Estudos sobre as Tecnologias da Informação e da Comunicação.

Painel IBOPE/NetRatings. 2011. Disponível em:

<http://www.cetic.br/usuarios/ibope/index.htm>. Acesso em: 16 abril 2011.

DUBNER, Alan. Mídia Social. Disponível em: 〈http://www.midiasocial.com.br/home/>. Acesso em: 16 abril 2011.

EXAME.COM. 98\% dos internautas brasileiros acessam redes sociais de casa. 2010. Disponível em: <http://exame.abril.com.br/tecnologia/noticias/98-internautas-brasileirosacessam-redes-sociais-casa-587599>. Acesso em: 07 maio 2011. 
EXAME.COM. Estudo mapeia passos virtuais das mulheres na internet, 2010. Disponível em: <http://veja.abril.com.br/noticia/vida-digital/estudo-mapeia-passos-virtuais-das-mulheresna-internet>. Acesso em: 07 maio 2011.

EXAME.COM. Veja a internet em números no ano de 2010. 2011. Disponível em:

$<$ http://exame.abril.com.br/tecnologia/noticias/veja-a-internet-em-numeros-no-ano-de-2010>. Acesso em: 16 maio 2011.

FACEBOOK. 2011. Facebook. Disponível em:

<https://www.facebook.com/index.php?lh=c21a89992551e432c24cbc0009050e1b\&eu=olo7 wW1iA04_IIUYwsugpA>. Acesso em 07 maio 2011

GIL, Antonio C. Como elaborar projetos de pesquisa. $4^{\text {a }}$ edição. São Paulo: Atlas - 2002.

GODOY, Arilda S. CUNHA, Maria A. V. C. Ensino em pequenos grupos. In: MOREIRA, Daniel A. (Org). Didática do Ensino Superior: Técnicas e Tendências. São Paulo: Pioniera, 1997.

GREGO, Maurício. Usuários passam 41 h por semana em redes sociais. 2011. Disponível em: <http://info.abril.com.br/noticias/internet/usuarios-passam-41h-por-semana-em-redessociais-25032011-44.shl>. Acesso em: 07 maio 2011.

HELLMANN, Géssica. O que é mídia social?. 2008. Disponível em:

<http://www.webartigos.com/articles/5560/1/O-Que-e-Midia-Social/pagina1.html>. Acesso em: 16 abril 2011.

IG. Último Segundo - Educação. Educador quer redes sociais no currículo escolar. 2011. Disponível em:

<http://ultimosegundo.ig.com.br/educacao/educador+quer+redes+sociais+no+curriculo+escol ar/n1238187320827.html>. Acesso em: 07 maio 2011.

KARASINSKI, Eduardo. Redes Sociais: Qual o perfil do brasileiro em cada uma delas?. 2010. Disponível em: <http://www.tecmundo.com.br/5913-redes-sociais-qual-e-o-perfil-dobrasileiro-em-cada-uma-delas-.htm>. Acesso em: 07 maio 2011.

MARION, José C. MARION, Luís C. Metodologias de ensino na área de negócios: Para Cursos de Administração, Gestão, Contabilidade e MBA. São Paulo: Atlas, 2006.

MORAN, José M. Como utilizar a internet na educação. 1997. Disponível em: <http://www.scielo.br/scielo.php?pid=s0100-19651997000200006\&script=sci_arttext>. Acesso em: 28 agosto 2011.

MOREIRA, Daniel Augusto (org). Didática do Ensino Superior: Técnicas e Tendências. Revisão Janice Yunes Perim. $1^{\mathrm{a}}$ Edição, $2^{\mathrm{a}}$ Reimpressão. São Paulo: Pioneira Thomson Learning, 2003).

NÉRICI, Imídeo G. Metodologia do ensino: uma introdução. $4^{a}$ edição. São Paulo: Atlas, 1992. 
NUNES, Paulo. Conceito de .net. 2008. Disponível em: <http://www.knoow.net/ciencinformtelec/informatica/_net.htm> Acesso em: 18 setembro 2011.

OLIVEIRA, Silvio Luiz. Tratado de Metodologia Cientifica: Projetos de Pesquisa, TGI, TCC, Monografias, Dissertações e Teses. São Paulo: Pioneira Thomson Learning, 2002.

PORTAL DAS REDES SOCIAIS. Facebook deve ultrapassar o orkut até o final do ano. 2011. Disponível em: <http://grou.ps/redesocial/blogs/item/facebook-deve-ultrapassar-orkutate-o-fim-do-ano>. Acesso em: 07 maio 2011.

PORTAL DAS REDES SOCIAIS. Redes Sociais como fonte de conteúdo. 2011. Disponível em: 〈http://grou.ps/redesocial/blogs/item/redes-sociais-como-fonte-de-conte\%C3\%BAdo>. Acesso em: 07 maio 2011.

POZZEBON, Rafaela. Quais as expectativas para as redes sociais em 2011?. 2011. Disponível em:

<http://www.oficinadanet.com.br/artigo/midias_sociais/quais_as_expectativas_para_as_redes _sociais_em_2011>. Acesso em: 07 maio 2011.

RECUERO, Raquel. Cinco pontos sobre redes sociais na internet - Parte 1. 2009. Disponível em: <http://www.jornalistasdaweb.com.br/index.php?pag=displayConteudo\&idConteudo=3964> . Acesso em: 07 maio 2011.

ROSENBLOON, Stephanie. Escolhas demais para os 'plugados'. 2011. Disponível em: <http://nytsyn.br.msn.com/negocios/escolhas-demais-para-os-plugados> Acesso em: 28 agosto 2011.

SANTOS, Neide. Estado da arte em espaços virtuais de ensino e aprendizagem. 2008. Disponível em: <http://pt.scribd.com/doc/6795012/Neide-Santos-Espacos-Virtuais-deEnsino-e-Aprendizagem> Acesso em: 28 agosto 2011.

SIMON, Imre. A arpanet. 1997. Disponível em:

<http://www.ime.usp.br/ is/abc/abc/node20.html> Acesso em: 18 setembro 2011.

TELLES, Andre. Definição de rede social e mídia social. 2010. Disponível em: <http://www.midiatismo.com.br/comunicacao-digital/definicao-de-rede-social-e-midiasocial>. Acesso em: 07 maio 2011.

VEJA.COM. Nos laços (fracos) da internet. 2009. Disponível em: <http://veja.abril.com.br/080709/nos-lacos-fracos-internet-p-94.shtml> Acesso em: 21 de Outubro 2011.

WIKIPEDIA - A Enciclopédia Livre. Twitter. 2011. Disponível em: < http://pt.wikipedia.org/wiki/Twitter>. Acesso em: 07 de maio de 2011. - A Enciclopédia Livre. Orkut. 2011. Disponível em: < http://pt.wikipedia.org/wiki/Orkut> Acesso em: 07 de maio de 2011. 
- A Enciclopédia Livre. Wikipédia. 2011. Disponível em:

<http://pt.wikipedia.org/wiki/Wikipedia> Acesso em: 07 de maio de 2011.

- A Enciclopédia Livre. Second Life. 2011. Disponível em:

<http://pt.wikipedia.org/wiki/Second_life> Acesso em: 07 de maio de 2011.

- A Enciclopédia Livre. Facebook. 2011. Disponível em:

<http://pt.wikipedia.org/wiki/Facebook> Acesso em: 07 de maio de 2011.

- A Enciclopédia Livre. My Space. 2011. Disponível em:

<http://pt.wikipedia.org/wiki/My_Space> Acesso em: 07 de maio de 2011.

- A Enciclopédia Livre. You Tube. 2011. Disponível em:

<http://pt.wikipedia.org/wiki/YouTube> Acesso em: 07 de maio de 2011.

- A Enciclopédia Livre. Flickr. 2011. Disponível em:

<http://pt.wikipedia.org/wiki/Flickr > Acesso em: 07 de maio de 2011.

- A Enciclopédia Livre. Upcoming. 2011. Disponível em:

<http://en.wikipedia.org/wiki/Upcoming> Acesso em: 07 de maio de 2011.

ZEVALLOS JUNIOR, Ruben. A história da internet, 2009. Disponível em:

<http://www.artigonal.com/ti-artigos/a-historia-da-internet-737117.html>. Acesso em: 16 abril 2011. 